\title{
Effects of signaled retention intervals on pigeon short-term memory
}

\author{
EDWARD A. WASSERMAN \\ University of Iowa, Iowa City, Iowa \\ and \\ JAMES GROSCH and JOHN A. NEVIN \\ University of New Hampshire, Durham, New Hampshire
}

\begin{abstract}
In three delayed matching-to-sample experiments, pigeons were given distinctive stimuli that were either correlated or uncorrelated with the scheduled retention intervals. Experiment 1 employed a single-key, go/no-go matching procedure with colors as the sample and test stimuli; lines of differing orientations signaled short or long delays for one group, whereas the lines and the delays were uncorrelated for the other group. The function relating discriminative test performance to delay length was steeper in the correlated group than in the uncorrelated group. In addition, the line orientation stimuli controlled differential rates of sample responding in the correlated group, but not in the uncorrelated group. In Experiment 2, subjects extensively trained with correlated line orientations were exposed to reversed cues on probe trials. Miscuing decreased discriminative test responding at the short delay, but enhanced it at the long delay. As in the correlated group of the first experiment, rates of sample keypecking were higher in the presence of the "short" time tag than in the presence of the "long" time tag. Experiment 3 used a three-key choice-matching procedure and a withinsubjects design, and equated reinforcement rate at the short and long delays. When auditory stimuli were correlated with delay length, the function relating choice accuracy to delay was steeper than when the stimuli and the delays were uncorrelated. The consistent effects of signaled retention intervals on memory performance may be understood in terms of differential attention to the sample stimuli.
\end{abstract}

Recently, the delayed matching-to-sample paradigm (e.g., Blough, 1959) and its numerous procedural variants (e.g., Shimp \& Moffitt, 1977; Wasserman, 1976) have been used to investigate short-term memory in nonhuman subjects. Many of these studies of animal short-term memory have scheduled several different retention intervals during daily sessions, with the time values varying randomly and unpredictably from trial to trial.

An exception to this practice was an experiment by Perkins, Lydersen, and Beaman (1973). There,

Experiments 1 and 2 were conducted by E. A. Wasserman at the University of Iowa, with the support of the National Science Foundation (Grants BNS 75-15905 and 79-14160). Experiment 3 was conducted by J. Grosch and J. A. Nevin at the University of New Hampshire with the support of the National Science Foundation (Grant BNS 79-24082). The authors are indebted to M. Olson, F. Taylor, and T. Usiak for their assistance in the research. Portions of this work were reported at the 1980 meeting of the Psychonomic Society and at the 1981 meeting of the Eastern Psychological Association. Requests for reprints may be addressed to any of the authors: E. A. Wasserman, Department of Psychology, University of Iowa, Iowa City, Iowa 52242, and J. Grosch and J. A. Nevin, Department of Psychology, University of New Hampshire, Durham, New Hampshire 03824. pigeons were given stimuli that indicated not only which comparison stimulus to select at test, but also how long it would be until the memory test would be administered. These subjects showed generally better discrimination at 2-, 4-, and 6-sec retention intervals than other birds given the same delays, but nondifferentially associated with the sample stimuli.

These results are consistent with the proposal that information about the upcoming retention interval facilitates memory of the sample stimulus. Unfortunately, another equally plausible hypothesis can explain the results: Because they were consistently associated with the sample stimuli, the specific delay interval durations themselves could also have served as discriminative stimuli controlling test responding for the first group of subjects but not the second, thereby supporting superior discriminative responding (Stubbs, 1968).

The present study explored the influence of retention interval information on pigeon short-term memory, while eliminating the confounding in the investigation of Perkins et al. (1973). The tactic here was to add time tags to matching-to-sample procedures of the choice (Blough, 1959; our Experi- 
ment 3) and go/no-go varieties (Nelson \& Wasserman, 1978; our Experiments 1 and 2). The sample and test stimuli were chosen from a set of two colors, and the time tags were chosen from a set of two auditory stimuli (Experiment 3) or two line orientation stimuli (Experiments 1 and 2). The auditory and line orientation stimuli were arranged to tag the retention intervals in two ways: (1) by association with a particular ongoing retention interval and (2) by association with an upcoming retention interval of a specific value.

Performance under the informative time-tag procedure was compared with that under an uninformative procedure which involved the same auditory or line-orientation stimuli and retention intervals, but with no consistent interrelation. Both betweensubjects (Experiment 1) and within-subjects (Experiment 3) comparisons were made. As each contrast revealed a steeper short-term memory gradient under the informative tagging procedure than under the uninformative procedure, additional experiments and analyses investigated the source of this effect. Experiment 1 examined the role of differential responding during the sample stimulus and during the retention interval, Experiment 2 pursued the issue of differential sample responding in the informative procedure by using a miscuing technique, and Experiment 3 controlled for differences in the rate of reinforcement entailed by the various retention intervals so that the effects of those values per se might be clearly isolated.

\section{EXPERIMENT 1}

\section{Method}

Subjects. Sixteen experimentally naive adult feral pigeons were individually housed under 24-h room illumination, with water and grit always available in the home cages. The birds were maintained at $80 \%$ of their free-feeding body weights; in most cases, a pigeon's weight did not differ from the $80 \%$ value by more than $10 \mathrm{~g}$. Following the daily experimental sessions, the birds were fed additional grain, if necessary, to maintain their level of deprivation. Prior to the experimental training detailed below, the subjects were autoshaped to peck the key-light stimuli described in the following Apparatus section.

Apparatus. Four three-key pigeon chambers, each with only the center key operative, were used. The 19-mm-diam transparent plastic key required a peck force of more than $.05 \mathrm{~N}$ for activation and was located $94 \mathrm{~mm}$ above the solenoid-operated grain hopper and $49 \mathrm{~mm}$ below the houselight. The key could be transilluminated with orange $(O)$ or green (G) light, or with a white vertical $(\mathrm{V})$ or horizontal $(\mathrm{H})$ line centered on a black field, by a miniature display projector (IEE Series $10,28 \mathrm{~V} \mathrm{dc}$, CM 1820 bulbs). The white line stimuli had a width of $2 \mathrm{~mm}$ and length of $19 \mathrm{~mm}$. The luminance of the stimuli was measured with a Tektronix $\mathrm{J} 16$ digital photometer, $10 \mathrm{~mm}$ from the key surface. Luminance values for $O, G, V$, and $H$ stimuli were $14.5,5.1,2.5$, and $2.3 \mathrm{~cd} / \mathrm{m}^{2}$, respectively. An ESB 24 bulb illuminated the grain hopper with white light whenever the hopper was raised for reinforcement. The houselight ( $28 \mathrm{~V} \mathrm{dc}, \mathrm{CM} 1820$ bulb) was encased in a black metal housing that directed white light toward the ceiling. The interior walls of the chamber, including the response panel (which contained the pecking keys, houselight, and food hopper), were made of aluminum. Masking noise was always present in the room containing the experimental chambers. Ventilator fans in each box also masked extraneous sounds. In an adjoining room, scheduling of experimental sessions and data collection were managed by a DEC PDP-8/A minicomputer equipped with a solid state interface and the SKED software system.

Procedure. Daily sessions involved 64 trials that progressed through the following steps: intertrial interval, sample stimulus, retention interval, test stimulus, and trial outcome. During the 20 -sec intertrial interval, the response key was dark. The houselight was continuously illuminated during the first $19 \mathrm{sec}$ of each intertrial interval; then two .25 -sec-off $/ .25$-sec-on cycles of the houselight served to signal the onset of the sample stimulus.

Either orange or green was presented with equal probability on the response key as the sample stimulus. The first keypeck after $5 \mathrm{sec}$ terminated the sample stimulus; if no response occurred within $65 \mathrm{sec}$ of sample onset (a very rare event), the sample was automatically terminated. Keypecking during the first $5 \mathrm{sec}$ of the sample stimulus was recorded.

The retention interval followed offset of the sample stimulus. Two values were randomly scheduled in daily sessions: 1 and $5 \mathrm{sec}$ or 1 and $10 \mathrm{sec}$ (see ahead for details). During the retention interval, the houselight was on and keypecks were recorded.

During the test-stimulus step, either orange or green was presented on the response key. When the test stimulus involved the same color as the sample (O-O and G-G), trials were designated "positive"; when the test stimulus involved a color different from that of the sample (O-G and G-O), trials were designated "negative." On positive trials, the first keypeck after $5 \mathrm{sec}$ turned off the test stimulus; on negative trials, the test stimulus lasted exactly $5 \mathrm{sec}$. Keypecks during the first $5 \mathrm{sec}$ of test-stimulus presentation were recorded.

On both positive and negative trials, the trial outcome lasted $2.5 \mathrm{sec}$, during which the houselight was off. On positive trials, the food hopper was lighted and elevated. On negative trials, the trial outcome was blackout.

The subjects were divided into two groups, depending upon the relationship between the duration of the retention interval on a particular trial and the orientation of the white line stimulus that was projected on the key during the sample stimulus and the retention interval (always the same orientation during both steps of a given trial). In the correlated (C) group, one line orientation was consistently associated with the shorter of the two retention intervals, whereas the other line orientation was consistently associated with the longer of the two retention intervals. For half of the subjects in this group, the assignments were vertical = shorter and horizontal = longer; for the other half, the assignments were reversed. In the uncorrelated (U) group, the two line-orientation stimuli were equally often associated with the shorter and the longer of the two retention intervals in each daily session.

The experiment was conducted in two replications with eight birds serving in each. In Replication 1, retention intervals of 1 and $10 \mathrm{sec}$ were scheduled for $\mathbf{4 0}$ daily sessions; 80 daily sessions then followed during which the scheduled retention intervals were 1 and $5 \mathrm{sec}$. In Replication 2, retention intervals of 1 and $5 \mathrm{sec}$ were scheduled from the beginning of training, which lasted for 40 daily sessions.

Mean rates of keypecking were calculated during the sample stimulus and the retention interval in accordance with the retention interval scheduled on that trial. Thus, during the sample stimulus, C subjects might respond discriminatively according to the upcoming retention interval on that trial, whereas $U$ subjects would have no basis for responding discriminatively to the two lineorientation stimuli during the sample. During the retention interval, both groups could theoretically discriminate the duration of the retention interval after $1 \mathrm{sec}$, although the $\mathrm{C}$ group would have the benefit of the informative line-orientation stimulus.

Mean rate of keypecking during the test stimulus was calculated separately, depending on the prior retention interval and on whether the trial was a positive, matching one or a negative, nonmatching 
one. From the rates of responding on positive and negative trials, a discrimination index was calculated: Discrimination index = rate on positive trials $\div$ (rate on positive + negative trials). This index increases from .50 to 1.00 as discrimination rises from chance to perfect levels. A decrease in the discrimination index as the retention interval is lengthened is thus the empirical evidence upon which the inference of forgetting is based.

\section{Results}

The results of primary interest come from terminal discrimination performance. However, before proceeding to those data, general trends in the acquisition of the test discrimination are outlined.

During the first phase of training in the first replication, 1- and 10-sec retention intervals were scheduled. Here, the $\mathrm{C}$ group learned the test discrimination faster than the $U$ group, but only at the $1-\mathrm{sec}$ retention interval; at the 10 -sec retention interval, no learning seemed to have taken place in either group.

Given this learning failure, the second phase of training involved 1- and 5-sec retention intervals in an effort to raise test performance at the longer of the two retention intervals. The change proved effective, with test discrimination indexes rising from near .50 under $10 \mathrm{sec}$ at the end of Phase 1 to about .70 under $5 \mathrm{sec}$ at the end of Phase 2. Additionally, test performance generally dropped more precipitously from the shorter to the longer retention interval in the $\mathrm{C}$ condition than it did in the $\mathrm{U}$ condition.

Similar trends were seen in the acquisition phase of the second replication. Discrimination ratios rose faster at the 1-sec than at the 5-sec retention interval, and ratios came to fall more quickly from the 1- to the 5 -sec value in the $C$ condition than in the $U$ condition. Unlike the first replication, there was no consistent tendency for discrimination at the 1 -sec interval in the $\mathrm{C}$ condition to exceed that in the $\mathrm{U}$ condition.

The major trends in terminal performance of the $C$ and $U$ groups can most easily be seen when the last 4 days' data are graphically portrayed, as they are in Figure 1. This figure displays the mean terminal test discrimination indexes of both groups of subjects in each of the two replications. Across both groups of subjects and both replications, discriminative test performance reliably fell from the 1 - to the 5-sec retention interval $[F(1,12)=78.11, p<.001]$. Although the test performance of the two experimental conditions did not differ from one another overall, the conditions $\times$ retention interval interaction was reliable $[F(1,12)=25.37, p<.001]$, thereby suggesting more rapid forgetting in the $\mathrm{C}$ condition than in the $\mathrm{U}$ condition. This reliable interaction was followed up by simple main effects tests at each retention interval. While the scores of the $\mathrm{C}$ group were generally higher at the short delay and lower at the long delay than those of the $U$ group, neither of these trends was statistically significant. The replications factor was

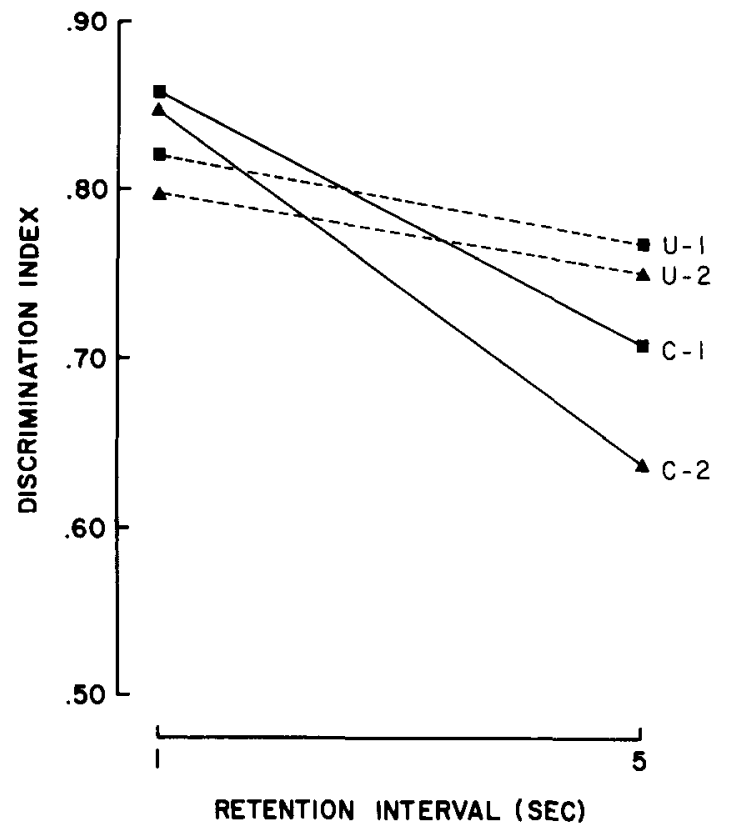

Figure 1. Mean discrimination indexes of correlated (C) and uncorrelated (U) groups at 1- and 5-sec retention intervals in each of the two replications (1 and 2) of Experiment 1.

not a reliable main effect, and it did not interact reliably with either of the other analysis factors. Subsequent data analyses therefore ignore it.

Aside from test-discrimination indexes, rates of keypecking during sample presentations, retention intervals, and test presentations over the final 4 days of training were examined for clues concerning why differential forgetting was seen in the $C$ and $U$ conditions.

The mean rates of keypecking during sample stimuli preceding 1- and 5-sec retention intervals are shown in the first panel of Figure 2 for the $C$ and $U$ conditions over the last 4 days of training. Although there was a reliable overall decrease in sample responding from 1 - to 5 -sec retention intervals $[F(1,14)=19.52$, $\mathrm{p}=.001]$, this decrease was due to the $C$ condition, as the conditions $\times$ retention interval interaction was reliable $[F(1,14)=26.24, p<.001]$. Simple main effect follow-ups at each retention interval failed to disclose reliable between-groups differences in responding. Thus, by keypecking at a higher rate prior to a 1-sec retention interval than prior to a $5-\mathrm{sec}$ interval, subjects in the $\mathrm{C}$ condition showed anticipation of the upcoming retention interval, whereas subjects in the $U$ condition did not (and presumably could not).

The mean rates of keypecking during the 1- and 5 -sec retention intervals over the last 4 days are shown in the second panel of Figure 2 for the $C$ and $U$ conditions. Analysis of variance indicated that neither group of subjects responded differently during the two retention intervals. 


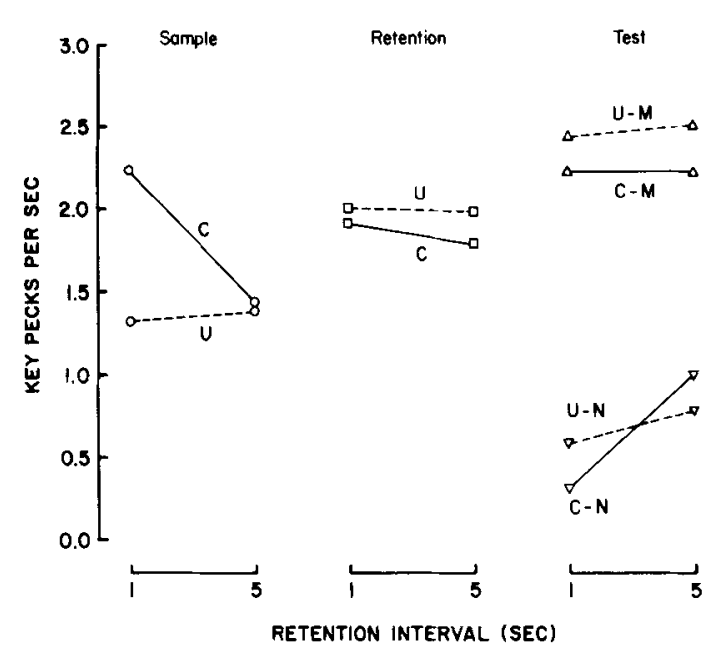

Figure 2. Mean rates of keypecking during the sample, the retention interval, and the test period for the correlated $(C)$ and the uncorrelated (U) groups in Experiment 1. Performance on 1- and 5 -sec trials is separately portrayed, as is performance on matching $(M)$ and nonmatching $(N)$ test periods.

The mean rates of keypecking on matching and nonmatching trials after 1 - and 5-sec retention intervals in the $C$ and $U$ conditions over the last 4 days are shown in the third panel of Figure 2. Response rates on positive, matching trials did not differ in either of the two conditions at either of the two retention intervals. Response rates on negative, nonmatching trials increased reliably as the retention interval increased from 1 to $5 \mathrm{sec}[\mathrm{F}(1,14)=23.37$, $\mathrm{p}<.001]$. Furthermore, the increase in rate was reliably greater in the $\mathrm{C}$ condition than in the $\mathrm{U}$ condition $[F(1,14)=6.90, p=.02]$. Simple main effects follow-up tests at each retention interval failed to divulge significant differences in responding between the two groups of subjects.

\section{Discussion}

The aim of this first experiment was to see if information concerning the upcoming and ongoing retention interval materially affects pigeon short-term memory. When terminal test performance under a successive matching-to-sample procedure was examined in terms of discrimination indexes derived from rates of keypecking on matching and nonmatching trials, the speed of forgetting was found to be faster when reliable time tags were provided than when they were not. Scrutiny of the rates of keypecking upon which the discrimination indexes were based revealed that the more rapid loss of discrimination in the $\mathrm{C}$ than in the $\mathrm{U}$ condition was the result of a more rapid rise in the rate of response on nonmatching trials; response rates on matching trials in the two conditions were unaffected by increases in the retention interval.

Other research on animal memory with the successive- matching procedure (e.g., Nelson \& Wasserman, 1978) has shown that forgetting is typically manifested by an increase in response rate on nonmatching trials, with little change in response rate on matching trials; when pigeons forget the sample stimulus, they are simply more likely to peck. Such a "go" bias (Weiskrantz, 1968) can readily be seen in the performance of both groups in the present experiment as the retention interval increased from 1 to $5 \mathrm{sec}$. The more rapid loss of discriminative performance in the $\mathrm{C}$ condition than in the $\mathrm{U}$ condition seen here was also the result of a selective change in the rate of response on negative trials, thus paralleling the memory loss commonly seen in prior research and within each condition of the present experiment.

Rates of responding during the samples and the retention intervals proved informative as well. $C$ subjects pecked more prior to the shorter retention interval than they did prior to the longer retention interval, but $U$ subjects did not. Also, neither group of subjects keypecked differently during the two scheduled retention intervals.

The overall pattern of results therefore suggests the following interpretation: When subjects are provided with reliable time tags during the sample stimulus, they peck more to the sample stimuli prior to the shorter retention interval than prior to the longer retention interval. Such a sample rate differential is probably due to the different delays to the test stimuli and/or to the trial outcomes that are entailed by the two retention intervals, and it likely leads to greater exposure to the sample stimuli prior to the shorter retention interval. Abundant evidence exists (e.g., Roberts \& Grant, 1976) showing that increasing exposure to a sample stimulus increases its memorability.

\section{EXPERIMENT 2}

Given that the pigeons in the $\mathrm{C}$ group of Experiment 1 keypecked more to the sample stimuli prior to the 1-sec retention interval than prior to the 5-sec interval and that such differential sample exposure might be instrumental in producing a steeper memory function in this group than in the $U$ group, a second experiment was conducted to pursue the matter further. After training subjects on the $\mathrm{C}$ procedure for an extended period of time, probe tests were given in which the upcoming retention intervals were either correctly cued as before (e.g., vertical = shorter and horizontal $=$ longer) or else the intervals were incorrectly cued (e.g., vertical = longer and horizontal = shorter). If miscuing were to lower test discrimination at the shorter retention interval and to raise test discrimination at the longer interval, then these results would add greater support to an attentional interpretation of the correlated-uncorrelated effect. 


\section{Method}

Subjects. Four experimentally naive feral pigeons were housed, deprived, and autoshaped to keypeck just as were those in Experiment 1 .

Apparatus. The apparatus was the same as that used in Experiment 1.

Procedure. The subjects were trained for 136 sessions in the same fashion as the four birds who served in the second replication of the $\mathrm{C}$ group in Experiment 1. Extended training was given to ensure that there was ample opportunity for each subject to master all of the discriminations involved in the present task, as all comparisons here were to be within individual subjects. On the following day, the first probe test was administered: Half of the retention intervals were correctly cued by line-orientation stimuli during the samples and the retention intervals, and half of the retention intervals were incorrectly cued. The next 6 days entailed retraining on the original $\mathrm{C}$ discrimination. On the following and final day, a second probe test, exactly like the first, was given.

\section{Results}

Figure 3 depicts the mean test discrimination indexes of the subjects on correctly cued and incorrectly cued trials averaged over both probe sessions, as analysis of variance failed to reveal any reliable main effects or interactions attributable to this factor. The figure and the reliable cuing $x$ retention interaction $[F(1,3)=11.55, p=.042]$ show that, whereas discriminative test performance on correctly cued trials fell from the 1- to the 5-sec retention interval, no such decrease occurred on incorrectly cued trials. In accordance with our predictions, discrimination on correctly cued 1-sec trials was reliably higher than on incorrectly cued $1-\mathrm{sec}$ trials $[\mathrm{t}(3)=2.80$, one-tailed $\mathrm{p}<.05$ ], and discrimination on correctly cued 5 -sec trials was reliably lower than it was on incorrectly cued 5 -sec trials $[\mathrm{t}(3)=2.96$, one-tailed $\mathrm{p}<.05]$.

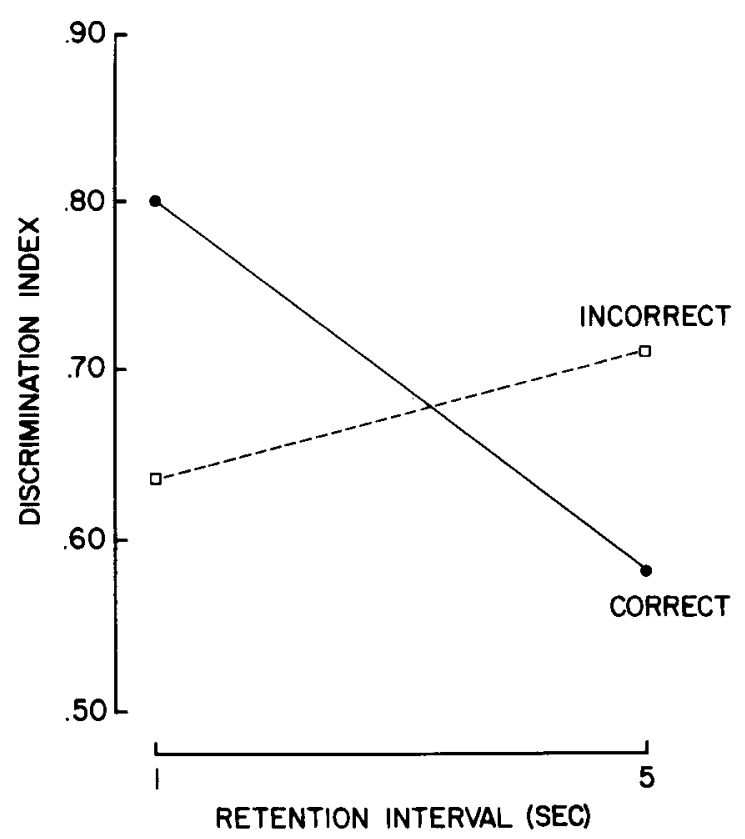

Figure 3. Mean dicrimination indexes on correctly cued and incorrectly cued trials in Experiment 2. Performance is separately pictured on 1- and 5-sec trials.
Table 1

Discrimination Indexes of Individual Subjects During the Probe Sessions of Experiment 2

\begin{tabular}{cccccc} 
& \multicolumn{2}{c}{ 1-Sec Delay } & & \multicolumn{2}{c}{5 -Sec Delay } \\
\cline { 2 - 3 } \cline { 5 - 5 } Test & $\mathrm{C}$ & $\mathrm{I}$ & & $\mathrm{C}$ & $\mathrm{I}$ \\
\hline & & Bird 1 & & \\
1 & .72 & .52 & .60 & .64 \\
2 & .80 & .71 & .69 & .66 \\
& & Bird 2 & & \\
1 & .66 & .62 & .49 & .61 \\
2 & .73 & .58 & .53 & .69 \\
& & Bird 3 & & \\
1 & .89 & .76 & .74 & .94 \\
2 & .73 & .69 & .71 & .83 \\
& & Bird 4 & & \\
1 & .95 & .65 & .41 & .67 \\
2 & .93 & .55 & .49 & .64 \\
\hline
\end{tabular}

Note-C = correct cuing; $I=$ incorrect cuing.

Table 1 shows the test-discrimination scores of each of the four birds at each retention interval under each condition of cuing on both probe sessions. These individual subject data can be seen to support the prior statistical claims.

As in Experiment 1, keypecking during the samples and during the retention intervals was recorded. The mean rate of sample responding in the presence of the "short" cue was 1.24 pecks/sec and in the presence of the "long" cue was .45 pecks/sec; all four birds pecked more to the "short" than to the "long" cue. The mean rate of retention interval responding after the "short" cue was 2.05 pecks/sec and after the "long" cue was 1.00 pecks $/ \mathrm{sec}$; three of the four birds continued to peck more after the "short" than after the "long" cue.

\section{Discussion}

As in Experiment 1, providing reliable time tags for the upcoming and ongoing retention interval yielded a steep short-term memory function across 1- and 5-sec delays. However, when the retention intervals were miscued, no such inverse function emerged. Cuing a short retention interval, but giving a long one, improved test performance at the long interval, whereas cuing a long retention interval, but giving a short one, impaired test performance at the short interval. Furthermore, the birds pecked the sample stimuli more on trials with a "short" time tag than on trials with a "long" time tag.

These results are in good agreement with the notion that cues tagging the shorter retention interval lead to greater exposure to the sample stimuli than do cues tagging the longer retention interval. The results fail to support the alternative idea that retentioninterval-specific behaviors are established to the two time tags: Such behaviors would be responses other than keypecking that would be called forth by the 
time tags, continue during the retention intervals, and provide discriminative support for later test responding. If this hypothesis were true, then test performance should have been worse on both miscued 1- and 5-sec trials than on their correctly cued counterparts, owing to generalization decrement.

\section{EXPERIMENT 3}

Experiment 1 demonstrated that the correlation of distinctive external stimuli with different retention intervals markedly influenced pigeon short-term memory. Relative to an uncorrelated control, the correlated procedure generally steepened the shortterm memory function. One factor that may play a role in the differential effect of correlated retention stimuli is the rate of reinforcement obtained by the subject at each retention interval. For example, estimating on the basis of the time from onset of the retention interval to trial termination, reinforcement rate in Experiment 1 was $1 / 6 \mathrm{sec}$ (or $10 / \mathrm{min}$ ) on positive $1-\mathrm{sec}$ delay trials, and $1 / 10 \mathrm{sec}($ or $6 / \mathrm{min}$ ) on positive 5-sec delay trials. Stimuli correlated with the retention intervals should presumably facilitate discrimination of these reinforcement rates by comparison with uncorrelated stimuli, as in multiple vs. mixed schedules of reinforcement (cf. Ferster \& Skinner, 1957). If test performance is positively related to the rate of reinforcement, then the differences in test discrimination with correlated and uncorrelated stimuli are as expected.

Because directly relevant data were lacking, we explored this possibility by arranging equated rates of reinforcement after short and long retention intervals and then assessed the effects of stimuli either correlated or uncorrelated with the length of the intervals. If the effects of correlated stimuli depend on differences in reinforcement rate obtained at different retention intervals, then equalizing the rate of reinforcement should lead to comparable performance with both correlated and uncorrelated stimuli.

Experiment 3 was conducted independently, without prior knowledge of Experiment 1, and it used a somewhat different procedure. The method was the more conventional delayed matching-to-sample task (Blough, 1959), with proportion of correct choices rather than discrimination index as the dependent variable. In addition, rather than using independent groups, we exposed individual subjects alternately to the correlated and uncorrelated conditions.

\section{Method}

Subjects. Four adult White Carneaux pigeons (Birds 8, 47, 48, and 49) were maintained at approximately $80 \%$ of their freefeeding weights through supplementary feedings following each experimental session. The subjects were individually housed with water and grit always available in the home cages. All birds had had extensive prior experience with delayed matching-to-sample procedures involving a variety of different retention intervals.

Appantus. The experimental chamber, $35 \times 30 \times 36 \mathrm{~cm}$, contained three Lehigh Valley plastic response keys located on the front wall. Each key, $26 \mathrm{~mm}$ in diameter, could be transilluminated with a $28-\mathrm{V}$ dc red, green, or white light and required $.16 \mathrm{~N}$ of force for an effective keypeck. A Lehigh Valley solenoidoperated food hopper was situated $90 \mathrm{~mm}$ directly below the center key. Located behind the front wall, $90 \mathrm{~mm}$ to the left of the food hopper, was an 89-mm speaker that was used to present either tone or white noise stimuli to the subject. The front wall was steel, and the remaining three walls and ceiling were aluminum; the floor of the chamber consisted of a steel grating. Chamber illumination was provided by an overhead $28-\mathrm{V}$ dc houselight. An exhaust fan provided constant masking noise. The experiment was initially controlled and monitored by electromechanical equipment and later by a DEC LSI-11 minicomputer located in an adjoining room.

Procedure. Daily sessions involved 100 trials, with each following a progression similar to that described in Experiment 1.

For the first $20 \mathrm{sec}$ of the intertrial interval, the response keys in the chamber were dark while the overhead houselight remained continuously on. After $20 \mathrm{sec}$, the center key was illuminated with a white light. A single peck to the center key produced the sample stimulus.

The sample stimulus was either a red or a green light, each color occurring with equal probability, illuminating the center key for $5 \mathrm{sec}$. Pecks to the center key during this period had no effect on the duration of the sample stimulus and, unlike in Experiments 1 and 2, were not recorded. Accompanying the sample stimulus was either a $750-\mathrm{Hz}, 85-\mathrm{dB}$ tone or an $85-\mathrm{dB}$ white noise stimulus. In the correlated $(C)$ condition, the tone always signaled that an 8-sec retention interval would follow, whereas white noise indicated that a 2 -sec retention interval would follow. In the uncorrelated (U) condition, the tone and white noise stimuli signaled each retention interval equally often.

A retention interval of either 2 or $8 \mathrm{sec}$, each duration occurring with equal probability, followed offset of the sample stimulus. During the retention interval, all lights in the chamber were extinguished. The same auditory stimulus that had accompanied the sample stimulus remained on.

Testing was signaled by houselight onset and illumination of the side keys with red and green lights. A peck to the side key whose color matched that of the sample stimulus (correct response) immediately terminated the auditory stimulus and the side keylights and became eligible for reinforcement. An incorrect response turned off the same chamber stimuli, but did not result in an opportunity for reinforcement.

Whether or not a correct response was actually reinforced was determined as follows: Reinforcement for a correct response was assigned following a 2 -sec retention interval with probability .25 and following an 8-sec retention interval with probability 1.00 . Once a reinforcer was assigned, no other reinforcers were available until it was obtained. This procedure ensured that a subject would receive reinforcement about four times as often following the 8-sec retention interval as following the 2 -sec retention interval if errors were randomly distributed, even if choice accuracy varied with the retention interval. When delivered, reinforcement consisted of 2.5-sec access to mixed grain. An incorrect response, or a correct response that was not reinforced, produced the same 2.5 -sec period but without hopper activation. Immediately following this trial outcome period, the intertrial interval began.

The subjects were trained in a repeated measures ABAB design. For Birds 48 and 49 , the $A$ condition involved the presentation of correlated signals, whereas the $B$ condition involved the presentation of uncorrelated signals. For Birds 8 and 47, the A and B conditions were reversed. Training continued in each condition until matching accuracy became relatively stable by visual inspection after a minimum of 13 sessions or for a maximum of 25 sessions. Actual numbers of sessions in each condition are given in Table 2. 


\section{Results}

Reinforcement-rate ratios were calculated for each subject, comparing the overall rates of reinforcement received following the 2 - and 8 -sec retention intervals. These ratios were expressed as the reinforcement time (in seconds) each subject received following the 2-sec retention intervals divided by 2 , divided by the reinforcement time (in seconds) received following the 8 -sec retention intervals divided by 8 . Identical rates of reinforcement would yield a ratio of 1.00 . The obtained ratios ranged from .94 for Bird 48 to 1.08 for Bird 47 , with a mean of .98 . Differences in individual ratio values were not associated with differences in discriminative performance.

The mean proportions of correct choice responses for the subjects at the 2- and 8-sec retention intervals during $C$ and $U$ training are pictured in Figure 4. These scores are averaged over both exposures to each of the two experimental conditions, as analysis of variance failed to reveal any reliable differences attributable to the replications factor. Overall, discriminative test performance reliably fell from the 2to the 8-sec retention interval $[F(1,3)=20.03, p=$ $.021]$. Although test performance under the two experimental conditions did not differ from one another overall, the conditions $\times$ retention interval interaction was reliable $[F(1,3)=28.67, p=.013]$, thus revealing more rapid forgetting in the $\mathrm{C}$ condition than in the $\mathrm{U}$ condition. The reliable interaction was followed up by simple main effects tests at each retention in-

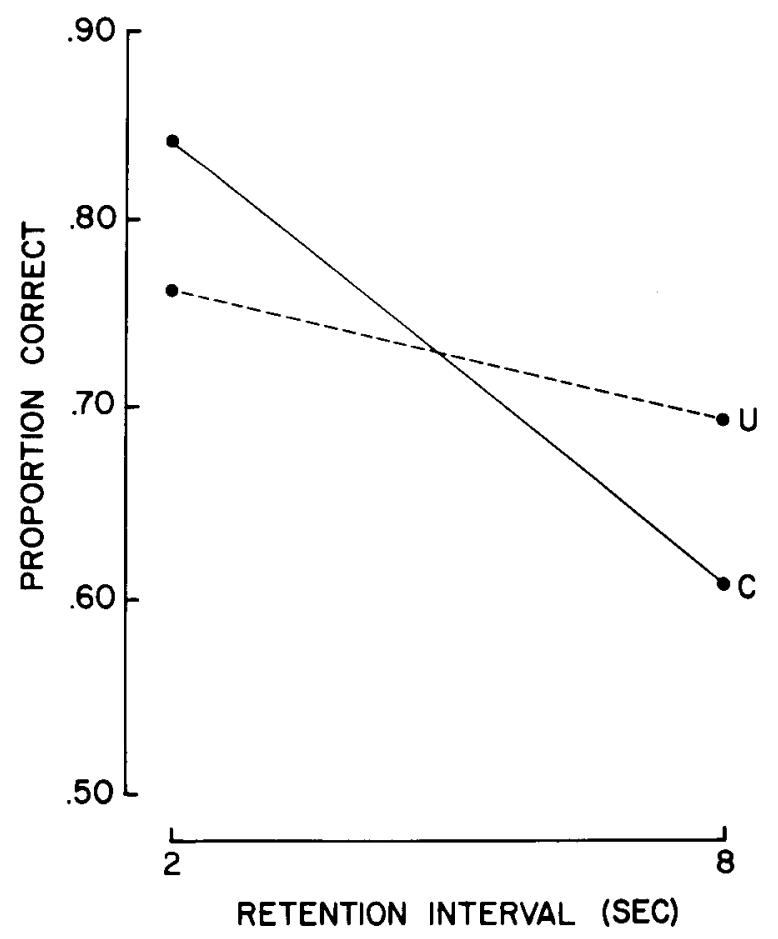

Figure 4. Mean proportion of correct choice responses during correlated (C) and uncorrelated (U) training at 2- and 8-sec retention intervals in Experiment 3.
Table 2

Proportion of Correct Choices by Individual Subjects Under the Correlated (C) and Uncorrelated (U) Treatments of Experiment 3

\begin{tabular}{ccccc}
\hline & & & \multicolumn{2}{l}{ Retention Interval } \\
\cline { 3 - 4 } Phase & Condition & Sessions & $2 \mathrm{Sec}$ & $8 \mathrm{Sec}$ \\
\hline & & Bird 8 & \\
1. & $\mathrm{U}$ & 13 & .73 & .70 \\
2 & $\mathrm{C}$ & 13 & .81 & .60 \\
3 & $\mathrm{U}$ & 14 & .79 & .71 \\
4 & $\mathrm{C}$ & 13 & .90 & .70 \\
& & Bird 47 & & \\
1 & $\mathrm{U}$ & 20 & .75 & .70 \\
2 & $\mathrm{C}$ & 15 & .83 & .66 \\
3 & $\mathrm{U}$ & 17 & .70 & .65 \\
4 & $\mathrm{C}$ & 25 & .77 & .62 \\
& & Bird 48 & & \\
1 & $\mathrm{C}$ & 15 & .93 & .57 \\
2 & $\mathrm{U}$ & 25 & .97 & .86 \\
3 & $\mathrm{C}$ & 13 & .97 & .57 \\
4 & $\mathrm{U}$ & 15 & .94 & .80 \\
& & Bird 49 & & \\
1 & $\mathrm{C}$ & 15 & .84 & .59 \\
2 & $\mathrm{U}$ & 25 & .67 & .58 \\
3 & $\mathrm{C}$ & 13 & .69 & .55 \\
4 & $\mathrm{U}$ & 15 & .55 & .55 \\
\hline
\end{tabular}

Note-The data are means for the last five sessions in each condition. Sequence of exposure to the conditions and numbers of sessions per condition are also shown.

terval. Although the scores in the $\mathrm{C}$ condition were generally higher at the short delay and lower at the long delay than those in the $U$ condition, neither of these trends was statistically significant.

Table 2 shows the test scores of each of the four birds at each retention interval under each experimental condition during each procedural exposure. These individual subject data support the prior statistical inferences.

\section{Discussion}

The results of the present experiment closely parallel those of Experiment 1. Stimuli that were correlated with retention interval durations again produced a greater disparity in matching accuracy following short and long retention intervals than did uncorrelated stimuli.

The present experiment controlled for the variable of different reinforcement rates within trials by roughly equalizing overall reinforcement for the 2- and 8-sec retention intervals. The similarity in the results of Experiments 1 and 3 strongly suggests that rate of reinforcement is not a primary determinant of the differential effects of correlated and uncorrelated time tags. Indeed, the fact that subjects, even when presented with uncorrelated stimuli, matched more accurately following the shorter 2 -sec retention interval indicates that the duration of the retention interval takes precedence over the rate of reinforce- 
ment in determining matching performance. Finally, the similarity in the results of Experiments 1 and 3, conducted with quite different methodologies and time-tag stimuli, suggests that the effects of signals correlated with retention intervals are quite robust and general.

\section{GENERAL DISCUSSION}

The present study was inspired by the idea that informing a subject of how long an event was to be remembered would facilitate its retention. This hypothesis is consistent not only with intuitions as to what factors may enhance the memory of prior events, but also with the prior empirical report of Perkins et al. (1973).

Unfortunately, when the present study eliminated an important confounding in the investigation of Perkins et al., no general enhancement in memory performance was obtained. Instead, a steeper memory function was supported by correlated training than by uncorrelated training, with memory in the former condition tending to be better at a short retention interval and worse at a long retention interval. This pattern of results was obtained: (1) with both choice (Experiment 3) and go/no-go (Experiment 1) matchingto-sample procedures, (2) with both visual (Experiment 1) and auditory (Experiment 3) time-tag stimuli, (3) across groups of different subjects (Experiment 1) as well as for individual subjects given the different cuing procedures during successive phases of training (Experiment 3), and (4) with both equated (Experiment 3 ) and unequated (Experiment 1) rates of reinforcement at the short and long retention intervals.

To the above situational and procedural generality of differential memory with signaled and unsignaled retention intervals must also be added species generality: humans, too, show a steeper memory function, with better performance at short retention intervals but poorer performance at long retention intervals, on a paired-associate immediate memory task when informative time tags are provided than when they are not (Hinrichs \& Grunke, 1975). An account of this result would thus carry with it considerable breadth of applicability.

What best explains the differential memory observed with cued and uncued retention intervals? Presently, differential attention to the sample stimulus appears to be the best candidate. First, only pigeons in our $\mathrm{C}$ condition pecked the sample stimuli more prior to a cued short retention interval than prior to a cued long retention interval (Experiments 1 and 2). Second, nondifferential rates of keypecking were observed during the retention interval itself in both the $C$ and $U$ conditions (Experiments 1 and 2). And third, for $\mathrm{C}$ subjects, miscuing a long retention interval led to better discrimination than did correct cuing, whereas miscuing a short retention interval led to poorer discrimination than did correct cuing (Experiment 2). Signals for short and long retention intervals may then modulate memory performance by differentially exciting keypecking and any other attentional responses during sample stimulus presentation.

Other interpretive possibilities exist. For example, because subjects in the $\mathrm{C}$ condition may divide their limited attention between the sample and time-tag stimuli, the rate of loss of sample information may be increased relative to subjects in the $U$ condition, in which the line-orientation or auditory stimuli would not be expected to divert attention away from the sample stimuli (see Riley \& Roitblat, 1978, for further work on divided-attention effects). While this divided-attention account provides a reasonable interpretation of the retention results of Experiments 1 and 3, it fails to predict the miscuing results of Experiment 2.

A third notion is related to the divided attention hypothesis. If the amount of delayed control exerted by prior sample stimuli is associated with the degree to which they control sample-specific responding (e.g., Urcuioli \& Honig, 1980), then perhaps the presence of reliable time tags makes responding to the sample stimuli more similar, and thereby reduces memory performance relative to a procedure without reliable time tags. To test this notion, we looked at sample responding in Experiment 1, now from the perspective of determining if the difference in the rate of response to the two sample stimuli was greater in the $U$ than in the $C$ condition. To this end, we computed for each subject the percentage of total sample keypecks that were made to the more-respondedto sample color over the last 4 days of training. The mean percentage was 56.65 in Group $U$ and 55.91 in Group $\mathrm{C}-\mathrm{a}$ nonsignificant difference. Thus, so far as keypecking is concerned, there was no tendency for the presence of reliable time tags to make pecking the two sample stimuli more nearly equal than training in the absence of reliable time tags.

However the time tags modulate memory performance, cues not necessary for accurate test discrimination (the time tags) strongly influenced the control exerted by cues that were necessary for accurate test discrimination (the sample stimuli). Yet to be determined is whether the presentation of stimuli signaling such parameters of reinforcement as its probability, quantity, and quality will also modulate sample stimulus memory. Also unknown is the influence of the time of such information transmittancebefore, during, or after sample presentation. Elucidation of these issues may well lead to data that will join the results of research on directed forgetting (e.g., Grant, 1981; Kendrick, Rilling, \& Stonebraker, 1981; Maki \& Hegvik, 1980) in showing that the processes of short-term memory are rather more dynamic 
and flexible than implied by many accounts of delayed discrimination in animals (e.g., D'Amato, 1973; Roberts \& Grant, 1976).

\section{REFERENCES}

Blough, D. S. Delayed matching in the pigeon. Journal of the Experimental Analysis of Behavior, 1959, 2, 151-160.

D'Aмато, M. R. Delayed matching and short-term memory in monkeys. In G. H. Bower (Ed.), The psychology of learning and motivation: Advances in research and theory (Vol. 7). New York: Academic Press, 1973.

Ferster, C. B., \& Skinner, B. F. Schedules of reinforcement. New York: Appleton-Century-Crofts, 1957.

Grant, D. S. Stimulus control of information processing in pigeon short-term memory. Learning and Motivation, 1981, 12, 19-39.

Hinfichs, J. V., \& Grunke, M. E. Control processes in shortterm memory: Use of retention interval information. Journal of Experimental Psychology: Human Learning and Memory, 1975, 104, 229-237.

Kendrick, D. F., Rilling, M., \& Stonebraker, T. B. Stimulus control of delayed matching in pigeons: Directed forgetting. Journal of the Experimental Analysis of Behavior, 1981, 36, 241-251.

Maki, W. S., \& Hegvik, D. K. Directed forgetting in pigeons. Animal Learning \& Behavior, 1980, 8, 567-574.

Nelson, K. R., \& Wasserman, E. A. Temporal factors influencing the pigeon's successive matching-to-sample performance: Sample duration, intertrial interval, and retention in- terval. Journal of the Experimental Analysis of Behavior, 1978, 30, 153-162.

Perkins, D., Lydersen, T., \& Beaman, D. Acquisition under mixed-delay and multiple-delay matching-to-sample. Psychological Reports, 1973, 32, 635-640.

Riley, D. A., \& Roitblat, H. L. Selective attention and related cognitive processes in pigeons. In S. H. Hulse, H. Fowler, \& W. K. Honig (Eds.), Cognitive processes in animal behavior. Hillsdale, N.J: Erlbaum, 1978.

Roberts, W. A., \& GRANT, D. S. Studies of short-term memory in the pigeon using the delayed matching-to-sample procedure. In D. L. Medin, W. A. Roberts, \& R. T. Davis (Eds.), Processes of animal memory. Hillsdale, N.J: Erlbaum, 1976.

Shimp, C. P., \& Moffit, M. Short-term memory in the pigeon: Delayed-pair comparison procedures and some results. Journal of the Experimental Analysis of Behavior, 1977, 28, 13-25.

Stuв8s, A. The discrimination of stimulus duration by pigeons. Journal of the Experimental Analysis of Behavior, 1968, 11, 223-238.

Uncuioli, P. J., \& Honig, W. K. Control of choice in conditional discriminations by sample-specific behaviors. Journal of Experimental Psychology: Animal Behavior Processes, 1980, 6, 251-277.

Wasserman, E. A. Successive matching-to-sample in the pigeon: Variations on a theme by Konorski. Behavior Research methods \& Instrumentation, 1976, 8, 278-282.

Weiskrantz, L. Memory. In L. Weiskrantz (Ed.), Analysis of behavioral change. New York: Harper \& Row, 1968.

(Manuscript received December 7, 1981; revision accepted for publication April 21, 1982.) 